\title{
Mortality and Morbidity Results Of Early Correlation Coronary Bypass Operations after Acute Myocardial Infarction
}

\author{
Orhan Rodoplu (Corresponding author) \\ Department of Cardiovascular Surgery, \\ Medicana Kadikoy Hospital, Istanbul, Turkey \\ E-mail: orhan.rodoplu@medicana.com.tr \\ Zafer Cengiz Er \\ Faculty of Medicine, Department of Cardiovascular Surgery, \\ Bozok University, Yozgat, Turkey \\ ORCID ID: 0000-0001-7129-1157 \\ E-mail: zafer.cengiz@yobu.edu.tr \\ Tamer Turk \\ Department of Cardiovascular Surgery, \\ Bursa Yuksek Ihtisas Training and Research Hospital, Bursa, Turkey \\ E-mail: tamer.turk@sbu.edu.tr
}

\begin{abstract}
In acute myocardial infarction (AMI) cases, mortality is highest in the first minutes of symptoms. Clinical observations emphasize the importance of providing myocardial reperfusion as soon as possible. Patients undergoing acute myocardial infarction (AMI) are initially treated medically. It has been shown that thrombolytic agents reduce mortality and protect ventricular function when used early. Together, thrombolytic therapy and angioplasty can provide the integrity and continuity of the coronary artery during MI.

The aim of the study: Patients with acute ST-segment elevation MI (STEMI) or acute non-ST segment elevation MI (NSTEMI) who were hospitalized for acute coronary angiography and isolated from coronary angiographies within 6 hours underwent elective coronary artery bypass surgery (CABS). The aim of this study is to compare the morbidity and mortality results of coronary artery disease after coronary angiography.

Patients and methods: 139 patients who underwent CABS between November 2011 and January 2013 were included in the study. 17 female, 62 male patients underwent early CABS after acute MI, 79 patients (group 1) with STEMI and NSTEMI with a mean age of $61.4 \pm 1$, The mean age was $60.1 \pm 1$ in the group consisting of 17 female and 43 male, and 60 patients (group 2) who did not undergo NSTEMI underwent early CABS.

Result: The increase in inotropic use and intensive care unit stay was statistically significant in patients with acute MI. There was no statistically significant difference between the two groups in terms of 24hour drainage amounts, excretion times, postoperative atrial fibrillation, cerebrovascular events and infection rates. There was no significant difference in total mortality.

Interpretation: CABS operation; It can be performed safely and successfully with acceptable mortality and morbidity rates in selected patients in the early period after acute MI.
\end{abstract}

Keywords: Acute myocardial infarction, Early - stage coronary artery bypass surgery.

\section{Special Issue of Health Sciences}

DOI: $10.7176 / \mathrm{JSTR} / 6-03-01$ 


\title{
Akut Miyokard İnfarktüsü Sonrası Erken Dönem Koroner BYPASS Operasyonlarının Mortalite ve Morbidite Sonuçları
}

\begin{abstract}
Özet
Akut myokard ınfarktus (AMI) olgularında mortalite, semptomların görüldüğü ilk dakikalarda en yüksek orandadır. Klinik gözlemler miyokardiyal reperfüzyonu en kısa sürede sağlanmanın önemini vurgulamaktadır. Akut miyokard infarktüsü (AMI) geçirmekte olan hastalar başlangıçta medikal olarak tedavi edilmektedir. Trombolitik ajanların erken dönemde kullanıldığında mortaliteyi azalttığı ve ventrikül fonksiyonlarını koruduğu gösterilmiştir Trombolitik terapi ve anjioplasti birlikte, MI sırasında koroner arter bütünlüğünü ve akım devamlılığını sağlayabilmektedir.

Çalışmanın amacı; Akut ST-Segment Elevasyonlu MI (STEMI) ya da akut Non-ST Segment Elevasyonlu MI (NSTEMI) tanısıyla hastaneye yatırılıp 6 saat içinde yapılan koroner anjiografileri sonucunda erken dönemde izole koroner arter bypass cerrahisi (KABC) uygulanan hastaların morbidite ve mortalite sonuçları ile, elektif koroner anjiografi sonrası koroner arter hastalığı saptanıp izole KABC uygulanan hastaların morbidite ve mortalite sonuçlarını karşılaştırmaktır.

Hastalar ve yöntem: Çalışmaya merkezimizde Kasım 2011-Ocak 2013 yılları arasında KABC uygulanan 139 hasta dahil edilmiştir. Akut MI sonrası erken dönem KABC uygulanan 17'si kadın, 62'si erkek, yaş ortalaması 61.4 \pm 1 olan STEMI veya NSTEMI geçirmiş 79 hastayla (grup 1), 17'si kadın 43'ü erkek olan yaş ortalamas $60.1 \pm 1$ olan STEMI veya NSTEMI geçirmemiş erken dönem KABC uygulanan 60 hasta (grup 2) karşılaştırılmıştır.

Sonuç: Akut MI geçirmiş grupta inotrop kullanımındaki ve yoğun bakım yatış süresindeki artı̧̧ istatiksel olarak anlamlı artmıştı. Her iki grupta 24 saatlik drenaj miktarları, extübasyon süreleri, postoperatif atrial fibrilasyon, serebrovasküler olay ve enfeksiyon oranları açısından karşılaştırıldığında istatistiksel olarak anlamlı farklılık tespit edilmedi. Total mortalitede anlamlı farklılık görülmedi.

Yorum: KABC operasyonu; Akut MI sonrası erken dönemde, seçilmiş hastalarda, kabul edilebilir mortalite ve morbidite oranlarılla güvenli ve başarılı bir şekilde yapılabilir.
\end{abstract}

Anahtar Kelimeler: Akut myokard infarktüsü, erken dönem koroner arter bypass cerrahisi.

\section{Giriş}

Akut myokard ınfarktus (AMI) olgularında mortalite, semptomların görüldüğü ilk dakikalarda en yüksek orandadır. Klinik gözlemler miyokardiyal reperfüzyonu en kısa sürede sağlanmanın önemini vurgulamaktadır. AMI geçirmekte olan hastalar başlangıçta medikal olarak tedavi edilmektedir. Trombolitik ajanların erken dönemde kullanıldığında mortaliteyi azalttı̆̆ 1 ve ventrikül fonksiyonlarını koruduğu gösterilmiştir. Trombolitik terapi ve anjioplasti birlikte, MI sırasında koroner arter bütünlüğünü ve akım devamlılı̆gnı sağlayabilmektedir (1). Koroner arter baypas cerrahisi (KABC) günümüzde tüm dünyada kalp cerrahisinde en sık yapılan ameliyat olarak literatürde yer almaktadır. KABC endikasyonu aldıktan operasyona kadar geçen sürenin uzaması hastalarda anksiyete, depresyon ve psikolojik gerginliğe sebep olmakta ve bu olumsuz etkilerin operasyondan sonra da devam ettiği bildirilmiştir (2). $\mathrm{Bu}$ yüzden ülkeler kendi sağlık sistemleri ve olanakları dahilinde $\mathrm{KABC}$ öncesi bekleme süresini en aza indirecek mekanizmalar ve algoritmalar geliştirme ve erken operasyondan en fazla yarar görecek hasta gruplarını belirleme çabasına girmişlerdir.

$\mathrm{Bu}$ çalışmanın amacı; Akut ST-Segment Elevasyonlu MI (STEMI) veya akut Non-ST Segment Elevasyonlu MI (NSTEMI) tanısıyla hastaneye yatırılıp 6 saat içerisinde yapılan koroner anjiografileri sonucunda operasyon kararı alınan hastalara erken dönemde uygulanan izole KABC operasyonlarının mobidite ve mortalite sonuçları ile, anjina şikayeti ile hastaneye başvurmuş, STEMI ya da NSTEMI geçirmeyen, yapılan elektif koroner anjiografileri sonucunda koroner arter hastalığı saptanıp izole KABC kararı alınmış hastaların erken dönemde uygulanan operasyonlarının morbidite ve mortalite sonuçlarının karşılaştırılmasıdır.

\section{Materyal ve Metod}

Merkezimizde (Bursa Yüksek İhtisas Eğitim ve Araştırma Hastanesi Kalp Damar Cerrahisi Kliniğinde ) Kasım 2011- Ocak 2013 yılları arasında KABC uyğulanan 139 hasta retrospektif olarak çalışmaya dahil

2| P a g e

www.iiste.org 
edildi. Hastalar akut MI tablosu olup olmamasına göre iki gruba bölündü. Bu olgulardan akut MI geçirmiş KABC uygulanan 79 hasta çalışma grubu (Grup 1; 62 erkek, 17 kadın, $61 \pm 5$ yaş ortalaması), akut MI geçirmemiş KABC uygulanan 60 hasta kontrol grubu (Grup 2; 43 erkek, 17 kadın, 60,1 19.9 yaş ortalaması) olarak belirlendi. STEMI yada NSTEMI tanısıyla hastaneye yatırılıp akut MI sonrası ilk 6 saat içinde koroner anjiografileri yapıldıktan sonra operasyon kararı alınan ve erken dönemde KABC uygulanan ardışık 79 hasta (grup 1) ile, elektif koroner anjiografileri sonucunda operasyon kararı alınmış ve KABC uygulanan ardışık 60 hasta (grup 2) olarak sınıflandırıldı. Hastaların demografik özellikleri, kardiyak öyküleri ve perioperatif verileri hastane kayıtlarından elde edildi. Hastaların postoperatif inotrop kullanımı, intra aorttik balon pompası (İABP) kullanım gereksinimi, drenaj miktarı, atrial fibrilasyon, yoğun bakım yatış süresi, reentübasyon,enfeksiyon, serebrovaskuler olay ,revizyon gibi morbiditeleri ve erken dönem mortalite verileri kayıt altına alınarak 30 gün süre ile takip edildi.

Çalışmaya Alınma Kriterleri: Bilgilendirme formunu okuyup, onam formunu imzalayan ve elektif koşullarda kardiyopulmoner baypas (KPB) kullanılarak açık kalp cerrahisi uygulanan, 18-90 yaş arası hastalar dahil edilmiştir. Preoperatif EF \%30 ve üstünde olan. Beklenen KPB zamanı 30 dakikanın üzerinde olan. Bilinen serebrovasküler olay ve stroke öyküsü olmayan, psikotik ve nevrotik hastalığ1 bulunmayan hastalar dahil edilmiştir.

Çalışmadan Çıkarılma Kriterleri: Bilgilendirme formunu okuyup onam vermeyen, bilinen malignitesi olan, preoperatif enfeksiyonu olan, preoperatif böbrek hastalığı tanısı alan (herhangi bir böbrek fonksiyon testinde bozukluk tespit edilen), preoperatif karaciğer hastalığı tanısı alan (karaciğer fonksiyon testlerinde bozukluk tespit edilen), bilinen kronik hastalığı olan, ejeksiyon fraksiyonu \% 30 ve altında olan, operasyon sonrası gelişen komplikasyon nedeniyle ikinci kez operasyona alınan hastalar değerlendirme dişı bırakılmıştır.

Cerrahi teknik: Genel anestezi altında supin pozisyonda primer mediyan sternotomi yapılır. Sonrasında ıntererior mamarian arter (IMA) ve sağ veya sol vena safena manga greftleri hazırlanır. Perikard açıldıktan sonra askıya alınır. Hastalara 300U/kg dozunda heparin verilir. Aortaya 2 adet purse string dikiş konulur. Aorta aortik kanül ile kanüle edilerek arteryel akım sağlanır. Sağ atrium apendiksden iki aşamalı kanul konularak venöz dönüş sağlanır. Asendana ortaya kardiyopleji için kanül yerleştirilir. Sistemik 1sı tüm hastalarda 28-32 santigrat derecede tutulur. KPB için hollow-fiber oksijanatör ve entegre arteryel filtre kullanılır. Asendan aortaya kros klemp konulur ve soğuk kan kardiyoplejisi antegrad ve/ veya retrograd yolla verilir. Distal korener anastomozları 7/0 prolen ile tamamlanır. Distal anostomozlar sonrası ısınmaya geçilerek kros klemp kaldırılır. Proksimal anostomozlar KBP altında kalp çalışırken tamamlanmaktadır. Ventriküle bir adet pace teli yerleştirilir. Hastanın 37 santigrat dereceye 1sınmasıyla ve diğer parametrelerin normale dönmesiyle KPB'den çıkılır. Kanama kontrolünü takiben gögüs tüpü mediastene ve toraks dreni sol toraksa yerleştirilir. Sternum, fasya ve ciltaltı dokular vicryl kullanılarak anatomik planda kapatılarak operasyona son verilir.

\section{İstatistik-Metod}

Çalışmada elde edilen veriler değerlendirilirken SPSS 16.0 programı kullanıldı.Kategorik değişkenler sayı (\%), sürekli değişkenler ortalama \pm standart sapma, dağılım düzensizliği olan sürekli değişkenler ortanca değer olarak ifade edildi. Veriler ortalama Fischer's Exact Test, Pearson Ki-kare, Independent Samples Test ile istatistiksel olarak değerlendirildi. $\mathrm{P}<0.05$ değeri istatistiksel olarak anlamlı kabul edildi.

\section{Bulgular}

Grup 1; Akut MI (STEMI ya da NSTEMI) sonrası koroner anjiografileri ilk 6 saat içerisinde yapıldıktan sonra operasyon kararı verilmiş ardışık 79 hastadan, grup 2 ise; elektif koroner anjiografi sonrası izole CABG uygulanan ardışık 60 koroner arter hastasından oluşuyordu. Hastaların ortalama yaşı grup 1'de $61.4 \pm 9.6$, grup 2'de 60.1 \pm 9.9 idi. Cinsiyetlere göre dağılımlara bakıldığında grup 1'de kadın/erkek oranı 17/62 \%21,52 - \%78,48; grup 2'de 17/43\% 28.33-\%71.66 idi (Tablo 1).

Grup 1'de akut MI sonrası hastalara CABG ortalama $7.2 \pm 3$ gün, median altı gün sonra uyguland1. Vakaların CABG uygulanma zaman aralığı 1-15 gün arasında idi .Her iki grup arasında demografik özellikler ve risk faktörleri açısından anlamlı farklılıklar yoktu. Preoperatif hasta özellikleri, eşlik eden hastalıkları, \% EF değerleri görülmektedir ( Tablo 1).

İntraoperatif hasta verileri ele alındığında, akut MI geçirmiş grupta (grup 1) greft sayısı daha fazla ( $3.3 \pm 1$ ' e karş1lı 3.2 $\pm 1, \quad \mathrm{P}=0.474)$, kros klemp süresi(66.1 \pm 28.7 dak. vs. 61.8 $\pm 27.2 \mathrm{dak} ; \mathrm{p}=0.382)$ ve kardiopulmoner bypass süresi ( $87.9 \pm 34 \mathrm{dk}$ 'ya karş1lık $80.8 \pm 33 \mathrm{dk}, \mathrm{P}=0.222$ ) daha uzun olmasına rağmen istatistiksel olarak anlamlı farklılık görülmemiştir (Tablo 2). 
Tablo 1: Preoperatif hasta özellikleri

\begin{tabular}{|c|c|c|c|}
\hline & $\begin{array}{l}\text { Grup 1: MI geçirip CABG } \\
\text { uygulanan koroner arter } \\
\text { hastaları }\end{array}$ & $\begin{array}{l}\text { Grup 2: MI geçirmeyip } \\
\text { CABG uygulanan } \\
\text { elektif koroner arter } \\
\text { hastaları }\end{array}$ & $\mathbf{P}$ \\
\hline Hasta sayısı(n) & 79 & 60 & \\
\hline Yaş(yıl) & $61.4 \pm 9.6$ & $60.1 \pm 9.9$ & .405 \\
\hline $\operatorname{DM}(\mathrm{n}, \%)$ & $29, \% 36.7$ & $21, \% 35$ & .835 \\
\hline $\mathrm{HT}(\mathrm{n}, \%)$ & $63, \% 79,7$ & $44, \% 73,3$ & .374 \\
\hline $\mathrm{HL}(\mathrm{n}, \%)$ & $45, \% 56,9$ & $28, \% 46,6$ & .229 \\
\hline Heredite $(\mathrm{n}, \%)$ & $41, \% 51,8$ & $16, \% 26,6$ & .003 \\
\hline $\mathrm{PAH}(\mathrm{n}, \%)$ & $1, \% 1,2$ & $4, \% 6,66$ & .109 \\
\hline Sigara(n,\%) & $56, \% 70.8$ & $41, \% 68,3$ & .619 \\
\hline $\mathrm{KOAH}(\mathrm{n}, \%)$ & $25, \% 31,6$ & $15, \% 25$ & .391 \\
\hline Pre-op B blokor kullanımı & $58, \% 73,4$ & $39, \% 65$ & .284 \\
\hline
\end{tabular}

Tablo 2: İntraoperatif hasta verileri

Grup 1: MI geçirip KABG uygulanan koroner arter hastaları
Grup 2: MI geçirmeyip

KABG uygulanan elektif koroner arter hastaları

\begin{tabular}{lccc}
\hline Greft sayis1 & $3.3 \pm 1$ & $3.2 \pm 1$ & .474 \\
Xklemp, dak. & $66.1 \pm 28.7$ & $61.8 \pm 27.2$ & .382 \\
KPB, dakika & $87.9 \pm 34$ & $80.8 \pm 33$ & .222 \\
\hline
\end{tabular}

MI: Myokard infarktüsü,KPB: Kardiyopulmoner Bypass, KABG: Koroner Arteryel Bypass Greftleme

Grup 1'de 20 hastaya postoperatif inotrop ilaç desteği gerekirken grup 2'de 7 hastaya gerekli olup istatistiksel olarak anlamlı farklılık saptanmıştır ( $\mathrm{p}=0.034)$ ( Tablo 3). Grup 1'de 13 hastaya, grup 2'de 4 hastaya postoperatif İABP kullanıldı. Her iki gruptada preoperatif IABP kullanımı olmamış tüm IABP destekleri pompadan çıkış ve düşük debi sendromu tedavisi amacı ile kullanılmıştır. Postoperatif İABP kullanımında grup 1'de grup 2 ile karşılaştırıldığında hafif artış saptanmıştır ancak; istatistiksel olarak anlamlı fark yoktur ( $\mathrm{p}=0.081) .24$ saatlik drenaj miktarları grup 1'de 418.9 \pm 201.4 cc, grup 2'de $377.5 \pm 109.1 \mathrm{cc}$ idi. Atrial fibrilasyon grup 1'de 17 ( \%21,5) hastada gelişirken grup 2'de 12( \%20)

4 I P a g e www.iiste.org 
hastada gelişti( $p=0.827)$. Postoperatif serebrovasküler olay grup 1'de 2 hastada, grup 2'de 3 hastada gelişti ( $\mathrm{p}=0.372$ ). Postoperatif enfeksiyon grup 1'de 2 hastada gelişirken grup 2'de gözlenmedi ( $\mathrm{p}=0321$ ). Yoğun bakım yatış süresi grup 1'de $2.7 \pm 1.4 \mathrm{iken}$, grup 2'de $2.1 \pm 1.2 \mathrm{idi}$. Yoğun bakım yatış süresinde grup 1'de grup 2 ile karşılaştırıldığında istatistiksel olarak anlamlı artış saptandı $(\mathrm{p}=0.025)$. Her iki grup bu veriler açısından karşılaştırıldığında inotrop ilaç kullanımı, İABP kullanımı veyoğun bakım yatış süresi dışında istatistiksel olarak anlamlı farklılık görülmemiştir ( $p>0.05$ ) ( Tablo 3).

Grup 1'de 5 hastada, grup 2'de 3 hastada mortalite mevcuttu. Her iki grupta hastane içi total mortalitede anlamlı farklılık görülmemiştir ( $\mathrm{p}=0.520)$ ( Tablo 4).

Tablo 3: Postoperatif hasta verileri

\begin{tabular}{lccc}
\hline & $\begin{array}{l}\text { Grup 1: MI geçirip } \\
\text { KABG uygulanan } \\
\text { koroner arter } \\
\text { hastaları }\end{array}$ & $\begin{array}{l}\text { Grup2: MI geçirmeyen (elektif) } \\
\text { KABG uygulanan } \\
\text { koroner arter } \\
\text { hastaları }\end{array}$ & P \\
\hline İnotrop kullanımı & $20, \% 25,31$ & $7, \% 11,6$ & .044 \\
İABP & $13, \% 16,4$ & $4, \% 6,6$ & .081 \\
Drenaj miktarı (cc) & $418.9 \pm 201.4$ & $377.5 \pm 109.1$ & .827 \\
Atrial Fibrilasyon & $17, \% 21,5$ & $12, \% 20$ & .025 \\
Yoğun bakım yatış süresi & $2.7 \pm 1.4$ & $2.1 \pm 1.2$ & .652 \\
Reentübasyon & $2, \% 2,5$ & $3, \% 5$ & .506 \\
Enfeksiyon & $2, \% 2,5$ & $0, \% 0$ & .652 \\
Serebrovasküler olay & $2, \% 2,5$ & $3, \% 5$ & 1.0 \\
Revizyon & $1, \% 1,2$ & $0, \% 0$ & \\
\hline
\end{tabular}

Tablo 4:Mortalite verileri

\begin{tabular}{lcccc}
\hline & & $\begin{array}{l}\text { Grup 1: MI geçirip } \\
\text { KABG uygulanan } \\
\text { koroner arter } \\
\text { hastaları }\end{array}$ & $\begin{array}{l}\text { Grup 2: MI geçirmeyip } \\
\text { KABG uygulanan elektif } \\
\text { koroner arter } \\
\text { hastaları }\end{array}$ & $\mathbf{P}$ \\
\hline Hastane içi mortalite & $\mathrm{n}(\%)$ & $5(\% 6)$ & $3(\% 5)$ & .520 \\
\hline
\end{tabular}

\section{Tartışma}

Akut MI sonrası cerrahi olarak koroner arter revaskülarizasyonunun optimal zamanlamasının ne olduğu halen tartışmalı, sonuçları değerlendirilen, netlik kazanmamış bir olgudur. Zorluklarına ve risklerine rağmen cerrahi revaskülarizasyonun mutlak endike olduğu durumlar vardır $(3,4,5)$.

Güncel cerrahi revaskülarizasyon yöntemlerimiz myokardiyal kaybı minimize etmesine ve reinfarktları azaltmasına rağmen; erken reperfüzyonun deneysel modellerde peri-infarkt hemoraji, ödem ve nekrozla sonuçlanabildiği gösterilmiştir $(6,7)$ Akut MI sonrası CABG'in zamanlaması ve cerrahi sonuçlarını inceleyen çok sayıda çalışma yapılmıştır. Çoğu çalışmada operasyona bağlı gelişen mortalite değişkeni 
dikkate alınarak operasyon zamanlaması gösterilmiştir. 1988-2010 yılları arasında yayınlanmış 18 çalışmanın 7'sinde (\%39) erken dönem CABG ile artmış mortalite oranları arasında bağımsız bir ilişki rapor edilmiştir. 7 çalışmanın 6'sı son dönemde yapılmış olan çalışmalardır (8-9). Diğer 11 (\%61) çalışmada $\mathrm{CABG}$ ile artmış mortalite oranları arasında bağımsız bir ilişki saptanmamıştır (10-11).

Acil cerrahi yapılan $(<24$ saat), post-MI stabil yada unstabil anjinası olan, 65 yaş üstündeki yüksek risk kategorisindeki hastalarda mortalite oranlarında artış görüldüğü gösterilmiştir $(12,13)$.

Tüm bu çalışmaların sonucunda STEMI ya da NSTEMI sonrasında erken dönem operasyona alınan yüksek riskli olmayan hastalarda erken dönem CABG ile operatif mortalite arasında ilişki saptanmamıştır (8) Çoğu çalışmada erken dönem CABG ile ilşkili artmış mortalite oranlarının operasyona kadar geçen zamandan ziyade riski arttıran ek faktörlerle ilişkili olduğu gösterilmiştir (11).

Thielmann ve ark. akut MI sonrası acil yada erken dönem alınan hastaların morbidite ve mortalite sonuçlarının prediktörlerini inceledikleri çalışmalarında NSTEMI ve elektif koroner vakalarında troponin değerlerinin $>1.5 \mathrm{ng} / \mathrm{ml}$ olduğu vakalarda operatif mortalitede artış saptamışlardır $(15,16)$. Benzer diğer çalışmalarda preoperatif troponin değerlerinin operatif mortalitenin güvenilir bir belirleyici faktörü olduğu gösterilmiştir (17).Ayrıca STEMI sonrası acil ve erken dönem CABG operasyonunun prediktörleri ve sonuçlarını inceledikleri çalışmalarının sonucunda; preoperatif kardiyojenik şokun, bayan cinsiyetin ve operasyona kadar geçen sürenin morbidite ve mortalite sonuçlarını etkileyen major değişkenler olduğunu raporlamışlardır $(18,16)$. Bu çalışmada akut MI sonrası ortalama hastane içi mortalite oranını \%8.7 bulmuşlardır (18). Akut MI sonrası ilk 6 saatte opere edilen grubun mortalite oranın $\% 10.8,7-24$ saat arasında opere edilen grubun mortalite oranını \%23.8, 1-3 gün arasında opere edilen grubun mortalite oranını \%6.7, 4-7 gün arasında opere edilen grubun mortalite oranını \% 4.2, 8-14 gün arasında opere edilen grubun mortalite oranını (\%2.4) bulmuşlardır. Akut MI semptomları başladıktan 6 saat içerisinde yapılan cerrahi revaskülarizasyonun $\% 10$ civarında mortalitesi olduğunu ve eğer mümkünse; STEMI hastalarının medikal tedavi ile hemodinamik olarak stabilize edilip cerrahi revaskülarizasyonun en az 3 gün ertelenmesinin mortalite oranlarını \% 25 kadar düşürdüğünü bildirmişlerdir (18). Lee ve ark. STEMI sonrası ilk 3 gün içerisinde CABG yapılan hastalarla, NSTEMI sonrası ilk 3 gün içerisinde CABG yapılan hastaların sonuçlarını karşılaştırdıklarında STEMI grubunda artmış mortaliteoranları saptamışlardır $(19,20)$. STEMI/NSTEMI sonrası erken dönem CABG operasyonlarının sonuçlarının karşılaştırıldığı 15 çalışmanın 5'inde STEMI lehine artmış mortalite oranları saptanmıştır .Diğer 10 çalışmada anlamlı farklılık saptanmamıştır (14).

Çalışmamızda akut MI (STEMI ya da NSTEMI) sonrası erken dönemde KABC (max. 15 gün içerisinde median 6 gün) yapılmasının mortalite oranlarını negatif etkilemediğini gösterdik. Grup 1'de hastaneiçi mortalite oranları 5 hasta ile \%6, Grup 2'de hastaneiçi mortalite 3 hasta ile \%5 idi. Aynı şekilde postoperatif major komplikasyonlar açısından da iki grup arasında istatistiksel olarak anlamlı fark bulunmad1. Grup 1'de inotrop ilaç kullanımı Grup 2'ye göre istatistiksel olarak anlamlı olarak fazla bulundu. Grup 1'de İABP kullanımında Grup 2'ye göre hafif artış saptandı ancak; istatistiksel olarak anlamlı farklılık bulunmadi.

\section{Sonuç}

CABG operasyonu; Akut MI sonrası erken dönemde, seçilmiş hastalarda, kabul edilebilir mortalite ve morbidite oranlarıyla güvenli ve başarılı bir şekilde yapılabilir.

Çalışmayı sınırlayan nedenler

$\mathrm{Bu}$ çalışma retrospektif, homojen hasta gruplarından oluşan bir çalışmadır. Hasta sayısının azlığı da çalışmanın sınırlayıcı faktörlerindendir. Farklı cerrah grupları tarafından yapılan ameliyatlar ve sonuçları incelenmiştir. Bu da standardizasyonu güç kılmaktadır.

\section{Referanslar}

[1] Bozat T, Sarıkamış Ç, Koca V, Yavuz Ş, Özdemir A. Akut Miyokard Infarktüsünde Primer Anjiyoplasti. Türk Kardiyol Dern Arş 1997;25:149-152

[2] Ulaş Mustafa M, Çağlı K, Lafç̧ı G, Gedik S, Korkmaz K, Paç M. Koroner Bypass Cerrahisi ve Psikiyatrik Komplikasyonlar. İÜ Kardiyol Enst Derg, 2007;6 (2):33-37.

[3] Caceres M, Weiman Darryl S : Optimal Timing of Coronary Artery Bypass Grafting in Acute Myocardial Infarction; Ann Thorac Surg 2012; 84: 17-24)

[4] Yavuz S, Eris C, Ata Y, Celkan A, Mavi M, ÖZDEMIR İ.A.: Akut Miyokard İnfarktüsünde Koroner Bypass Cerrahisi; Türk Gögüs Kalp Damar Cerrahisi Dergisi; Kasım 1998, Cilt 6, Sayı 6, Sayfa (lar), 465- 472.

6 I P a g e 
[5] Yavuz S. Surgery as early revascularization after acute myocardial infarction. Anadolu Kardiyoloji Dergisi 2008;8 Suppl 2: 84-92.

[6] Pirzada FA, Weiner JM, Hood WB Jr. Experimental myocardial infarction. 14. Accelerated myocardial stiffening related to coronary reperfusion following ischemia. Chest 1978;74:190-5.

[7] Roberts CS, Schoen FJ, Kloner RA. Effect of coronary reperfusion on myocardial hemorrhage and infarct healing. Am J Cardiol 1983;52:610-4

[8] Parikh SV, de Lamos JA, Jessen ME, et al; CRUSADE and ACTION Registry -GWTG Participants. Timing of in hospital coronary artery bypass greft surgery for non-ST segment elevation myocardial infarction patients: results from the National Cardiovascular Data Registry ACTION Registry-GTWG ( Acute Coronary Treatment and Intervention Outcomes Network Registry- Get With The Guidelines). JACC Cardiovascular Interview 2010; 3: 419-27.

[9] Lee DC, Oz MC, Weinberg AD, Ting W, Optimal timing of revascularization: transmural versus nontransmural acute myocardial infarction. Ann Thorac Surg 2001; 71: 1197-202.

[10] Lee JH, Murrell HK, Strony J, et al. Risk analysis of coronary bypass surgery after acute myocardial infarction. Int J Cardiol 1997; 69:209-16.

[11] Curtis JJ, Walls JT, Salam NH, et al. Impact of unstable angina on operative mortality with coronary revascularization at varying time intervals after myocardial infarction. $J$ Thorac Cardiovasc Surg 1991;102:867-873.

[12] Caceres M, Weiman Darryl S : Optimal Timing of Coronary Artery Bypass Grafting in Acute Myocardial Infarction; Ann Thorac Surg 2012; 84: 17-24).

[13] Thielmann M, Neuhauser M, Marr A, et al. Predictors and Outcomes of Coronary Artery Bypass Grafting in ST Elevation Myocardial Infarction. Ann Thorac Surg 2007;84:17-24

[14] Creswell LL, Moulton MJ, Cox JL, Rosenbloom M. Revascularization after myocardial infraction. Ann Thorac Surg 1995;60:19-26.

[15] Thielmann M, Massoudy P, Neuhauser M, et al. Prognostic value of preoperative cardiac troponin I in patients with non-ST-segment elevation acute coronary syndromes undergoing coronary artery bypass surgery. Chest 2005; 128:3526-36.

[16] Thielmann M, Massoudy P, et al. Risk stratification with cardiac troponin I in patients undergoing elective coronary artery bypass surgery. Eur J Cardiothorac Surg 2005;27:861-9

[17] Paparella D, Scrascia G, Paramythiotis A, et al. Risk stratification with cardiac troponin I to assess midterm risks of coronary bypass grafting operations in patients with recent myocardial infarction. Ann Thorac Surg 2010;89:696-702.

[18] Thielmann M, Massoudy P, Neuhauser M, et al. Prognostic value of preoperative cardiac troponin I in patients undergoing emergency coronary artery bypass surgery with non STelevation or ST-elevation acute coronary syndromes. Circulation 2006;114(1 Suppl):I448-53.

[19] Lee DC, Oz MC, Weinberg AD, Ting W. Appropriate timing of surgical intervention after transmural acute myocardial infarction. J Thorac Cardiovasc Surg 2003;125:115-9.

[20] Lee DC, Oz MC, Weinberg AD, Ting W, Optimal timing of revascularization: transmural versus nontransmural acute myocardial infarction. Ann Thorac Surg 2001; 71: 1197-202. 